\title{
Management of the recurrent sternal wound infection
}

\author{
Geoffrey G Hallock MD \\ Division of Plastic Surgery, St Luke's Hospital, Bethlehelm, Pennsylvania, USA
}

GG Hallock. Management of the recurrent sternal wound infection. Can J Plast Surg 1995;3(3):127-132. After adequate sternal debridement or resection for the treatment of a sternal wound infection, muscle flap obliteration of the resulting void has become an accepted standard. Unfortunately, recurrence is not an inconsequential risk as evidenced in six $(20.7 \%)$ of our patients over the last 10 years. Two of these patients required a second muscle flap transfer before obtaining a healed wound. Since the available regional options for appropriate vascularized flaps is limited, especially with the increased frequency in use of the internal mammary artery for coronary artery bypass grafting, great care must be observed in the selection process not just for closure of the initial wound, but in anticipation of untoward sequela. A schema prioritizing alternatives has been established, so as to maximize the benefit of our workhorse flaps, the pectoralis major or rectus abdominis muscles.

Key Words: Median sternotomy, Muscle flaps, Sternal wound infection

\section{Traitement de l'infection récidivante d'une plaie au sternum}

RÉSUMÉ: Après un débridement ou une résection sternale adéquate pour le traitement d'une infection de plaie sternale, l'oblitération du lambeau musculaire est devenue une norme acceptée. Malheureusement, la récurrence n'est pas un risque bénin, comme en font foi six de nos cas $(20,7 \%)$ échelonnés sur dix ans. Deux de ces patients ont nécessité un nouveau lambeau musculaire pour obtenir une cicatrisation. Étant donné que le choix de lambeaux adéquatement vascularisés est limité, et particulièrement compte tenu de la fréquence accrue d'utilisation de l'artère mammaire interne pour les interventions de chirurgie cardiaque, il faut choisir l'intervention avec grand soin, non seulement pour ce qui est de la fermeture de la plaie initiale, mais pour prévenir toute séquelle indésirable. Un schéma établissant des solutions de rechange a été mis sur pied pour maximiser les avantages de nos principaux lambeaux, le grand pectoral et le grand droit de l'abdomen.

The incidence of sternal wound infection following cardiothoracic surgery is relatively miniscule, and certainly not in excess of the general rate of wound infection after most elective operations (1). Unfortunately, for those so afflicted, this can be a devastating problem due to risks of generalized sepsis, uncontrolled hemorrhage or thrombosis, or seeding of prosthetic devices $(2,3)$. Survival has increased over the years paralleling the evolution in treatment from open dressings, closed methods with suction 
drainage, to the intrathoracic transfer of extrathoracic vascularized flaps which presently have become the standard for severe deep mediastinal infections (4-6). The use of muscle flaps has substantially reduced mortality, morbidity and length of hospital stay when compared with earlier approaches $(4,7)$.

The ultimate effectiveness of local vascularized flaps for sternal wound closure, including donor site morbidity, has had limited study on a long term basis. One large experience from the Mayo clinic had an astonishing $26 \%$ rate of recurrence of wound infections, requiring additional flap coverage in $40 \%$ of those (6). Further recurrence in $25 \%$ of these latter patients necessitated a third flap in $60 \%(6)$. Although the same flap was re-elevated whenever possible (6), the remaining options were severely limited. Therefore, any approach devised to treat the infected sternal wound must always consider this inherent risk of recurrence. Any selection process must be parsimonious in nature, using a single muscle whenever possible to not only preserve local function and aesthetics, but also assure the greatest diversity of future choices (4). A schema for the prioritizing of available flap options in anticipation of a possible recurrence should, at least on an intellectual level, be devised by the involved surgeon, as we have attempted here (Table 1).

TABLE 1: Sternal closure flap priorities

\begin{tabular}{|c|c|}
\hline Initial & Recurrent \\
\hline \multicolumn{2}{|l|}{ Intact IMA } \\
\hline $\begin{array}{l}\text { 1. Unilateral pectoralis major* } \\
\text { 2. Unilateral rectus abdominis }\end{array}$ & $\begin{array}{l}\text { 1. Readvancement of 'initial' flap } \\
\text { 2. Opposite pectoralis major } \\
\text { 3. Unilateral rectus abdominis } \\
\text { 4. Other** }\end{array}$ \\
\hline \multicolumn{2}{|l|}{ Unilateral absent IMA } \\
\hline $\begin{array}{l}\text { 1. Ipsilateral pectoralis major - rotation } \\
\text { 2. Contralateral rectus abdominis }\end{array}$ & $\begin{array}{l}\text { 1. Readvancement of 'initial' flap } \\
\text { 2. Contralateral pectoralis major } \\
\text { 3. Contralateral rectus abdominis } \\
\text { 4. Other }\end{array}$ \\
\hline \multicolumn{2}{|l|}{ Bilateral absent IMA } \\
\hline $\begin{array}{l}\text { 1. Unilateral pectoralis major - rotation } \\
\text { 2. Unilateral rectus abdominis - } \\
\text { costomarginal collaterals }\end{array}$ & $\begin{array}{l}\text { 1. Readvancement of 'initial' flap } \\
\text { 2. Opposite pectoralis major - rotation } \\
\text { 3. Unilateral rectus abdominis - } \\
\text { costomarginal collaterals } \\
\text { 4. Other }\end{array}$ \\
\hline
\end{tabular}

IMA Internal mammary artery. 1 Primary choice, 2 Secondary, etc. ${ }^{*}$ Unless specified, pectoralis muscle can be used either as a rotation-advancement flap (thoracoacromial pedicle) or turnover (segmental IMA perforator). ${ }^{* * O t h e r ~ f l a p s ~ i n c l u d e ~ o m e n t u m ~ o r ~}$ latissimus dorsi, external oblique, or bipedicle pectoralis major-rectus abdominis (8) muscles depending on availability 


\section{MATERIALS AND METHODS}

All sternal wounds from 1984 to 1994 which required vascularized flap closure were retrospectively reviewed. The initial reason for surgical intervention by the cardiothoracic service was variable in these 29 patients (Table 2). Thirty-two muscle and seven musculocutaneous flaps were needed, most often following debridement by the cardiothoracic surgeon. There were four perioperative deaths, but none due to persistant mediastinal sepsis. Three patients died long after discharge. Six patients $(20.7 \%)$ developed a recurrent sternal infection and two of these required transfer of an additional muscle flap before obtaining ultimate healing. One hundred percent of patients discharged after their closure by a muscle flap transfer eventually obtained a healed wound.

\section{Case 1}

A 70-year-old woman, 22 months after median sternotomy for left internal mammary artery coronary artery bypass grafting, developed a left mid-sternal abscess requiring bone and cartilage debridement by the cardiothoracic service (Figure 1). Twenty years previously she had had a left radical mastectomy for breast cancer followed by extensive radiation therapy. A skin grafted split pectoralis major muscle turnover flap, using the fourth and fifth intercostal segmental perforators, provided initial coverage. She did well for five months until another abscess presented in the same location. Wider debridement including the muscle flap was again performed by the cardiothoracic surgeons with removal of all exposed cartilage. Following reconsultation, a right rectus abdominis muscle flap and skin graft provided satisfactory healing sustained at 56 months of followup.

\section{Case 2}

Two weeks following median sternotomy with multiple coronary artery bypass grafts, including use of the left internal mammary artery, a 77-year-old man developed profound respiratory failure secondary to mediastinal sepsis. Wide debridement resulted in exposure of a bypass graft within a fibrinous, poorly granulating wound (Figure 2). After consultation, radical sternectomy was performed. Debridement had to be limited around the exposed heart for fear of initiating catastrophic hemorrhage or thrombosis. To minimize anaesthesia time in this moribund patient, a single flap was considered to be preferable. A de-epithelialized right vertical rectus abdominis musculocutaneous flap seemed suitable to fill the void that extended from the xiphoid to the manubrium. His condition almost immediately improved, and he was then uneventfully discharged.

Nine months later the patient presented to the emergency room with an abscess at the xiphoid level which spontaneously opened, and drained persistently for two months. A sinogram and computerized tomographic (CT) scan revealed a subcutaneous tract running superiorly to the lower neck. Exploration was advised when another fluctuant area began to develop at the upper end of the sternotomy scar. Methylene blue was instilled to stain the tract. The caudal portion of the incision was first reopened with careful preservation and retraction of the rectus musculocutaneous flap. The sinus tract adhered to the undersurface of the flap from pedicle to tip. All flap fat was soft and viable with no evidence of fat necrosis. No discrete mediastinal structures could be identified as scar tissue had healed over them. No infectious locus was found. 
TABLE 2: Profiles of Initial Sternal Wounds*

\begin{tabular}{|c|c|}
\hline Etiology & \\
\hline Median sternotomy & \\
\hline Coronary artery bypass & 23 \\
\hline Valve replacement & 4 \\
\hline Metastatic osteomyelitis & 2 \\
\hline Total patients & 29 \\
\hline Wound class & \\
\hline Type I (acute) & 0 \\
\hline Type II (subacute) & 21 \\
\hline Type III (chronic) & 8 \\
\hline Flap selection & \\
\hline Pectoralis major muscle & \\
\hline Rotation-advancement & 18 \\
\hline Turnover & 3 \\
\hline Rectus abdominis: & \\
\hline Muscle (IMA intact) & 7 \\
\hline Muscle (IMA absent) & 4 \\
\hline VRAM & 3 \\
\hline De-epithelialized VRAM & 4 \\
\hline Other & none \\
\hline Total flaps & 39 \\
\hline Mortality & \\
\hline Perioperative & 4 \\
\hline During follow-up period & 3 \\
\hline Infection recurrence & \\
\hline Source & \\
\hline Osteomyelitis & 5 \\
\hline Unknown & 1 \\
\hline Initial wound & \\
\hline Type II & 5 \\
\hline Type III & 1 \\
\hline Mean onset & 7.4 months \\
\hline Total patients & 6 \\
\hline
\end{tabular}

*Entire experience from 1984 to 1994. $†$ Criteria per Pairolero and Arnold (6) as described in Results. IMA Internal mammary artery; VRAM Vertical rectus abdominis musculocutaneous flap 
Hallock
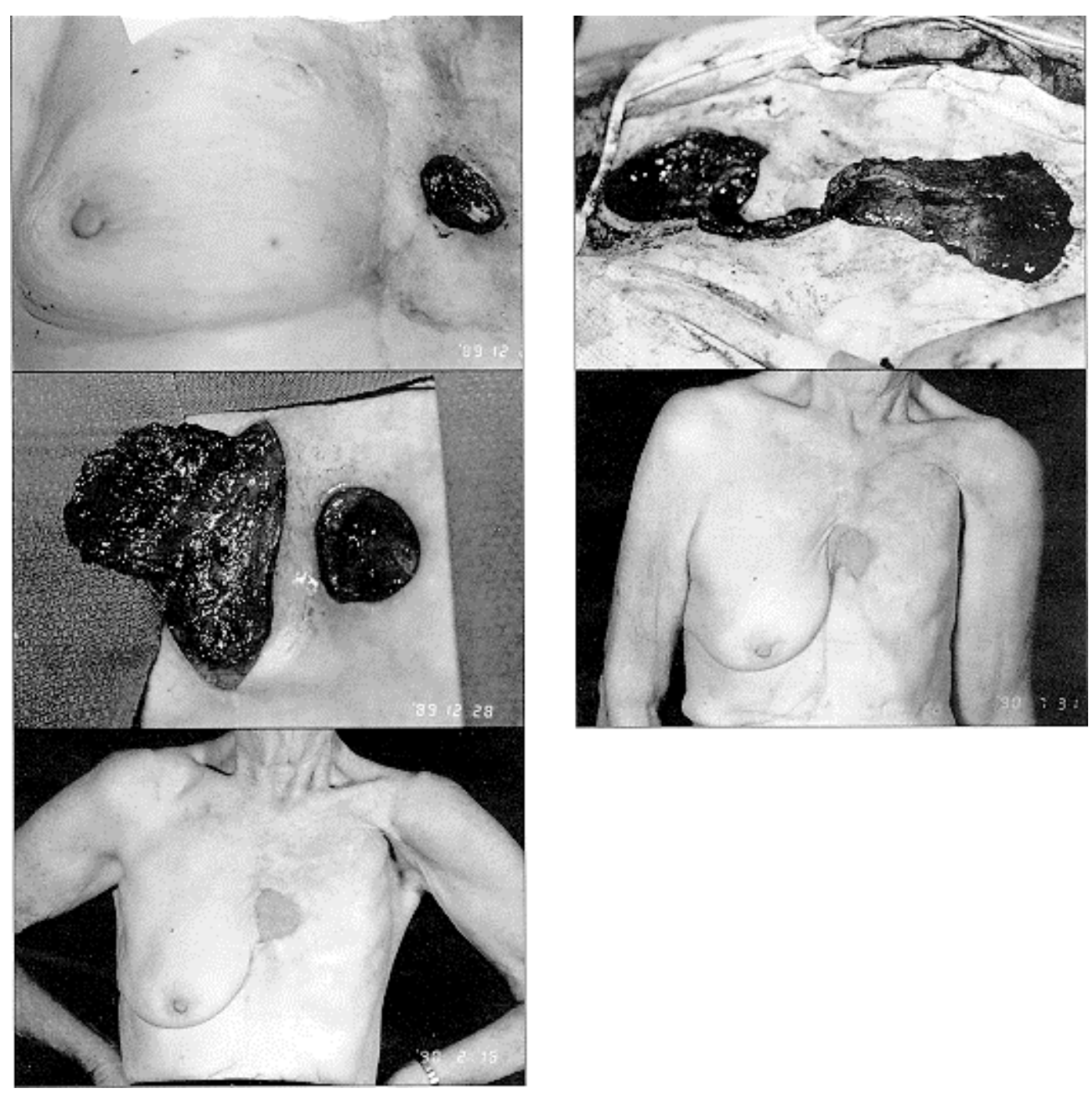

Figure 1) (Top left) Initial open wound. (Middle left) Split right pectoralis major muscle selected for original coverage which was raised by reopening median sternotomy incision. (Bottom left) Skin grafted muscle with early satisfactory wound healing. (Top right) Right rectus abdominis muscle harvested in preparation for turnover into redebrided defect (above) after a recurrence. (Bottom right) Ultimate success following transfer of this second muscle flap 

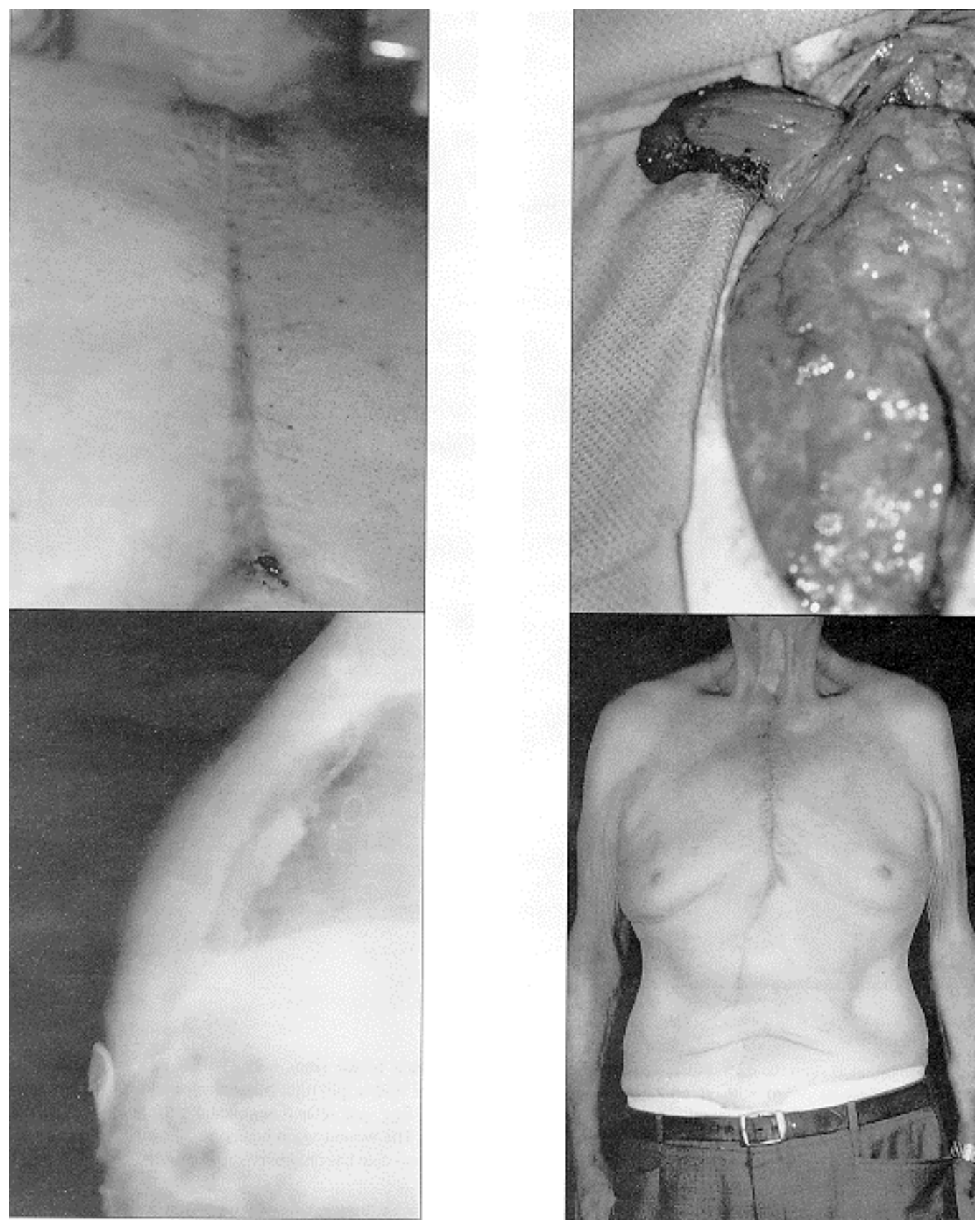

Figure 2) (Top left) Draining orifice (bottom) at xiphoid level of median sternotomy scar. (Bottom left) Sinus cavity leading upward underneath the flap as seen on a lateral chest sinogram. (Top right) During exploration of the sinus tract, the rectus abdominis muscle was salvaged intact with its composite fat paddle noted to fill almost the entire reopened median sternotomy incision. Superiorly, a right split pectoralis major muscle flap has been dissected for filling in a remaining void in the manubrial area. (Bottom right) Totally healed sternal wound 15 months after initial flap coverage, and three months after recurrence (vertical paramedian donor site scar seen in right abdomen) 
Following removal of all granulation tissues, the original flap again easily filled the majority of the defect created. Unfortunately, superiorly another mesothelial lined cavity near his tracheotomy site was accidently found which was not connected to the sinus tract. To fill this and the residual inferior void, a split right pectoralis major turnover flap based on the first and second segmental perforators was rapidly raised. The wound again healed satisfactorily, although follow-up to date has only been three months.

\section{RESULTS}

The majority of our patients suffering sternal infections had undergone median sternotomy for coronary artery bypass (Table 2). Following the wound classification schema of Pairolero and Arnold (6), no sterile dehiscences (type I) were treated by us. Most $(72.4 \%)$ were subacute wounds characterized by mediastinal suppuration and sternal osteomyelitis (type II) that had already been debrided by the cardiothoracic service, so that a delayed closure following a course of dressing changes was always required. The remaining patients with chronic draining sinuses or exposed wires $(17.6 \%)$ (type III) could be debrided by us (except in case 1), resulting in a more pristine wound defect that permitted a single stage closure.

TABLE 3: Comparison of incidence of recurrent sternal wound infections

\begin{tabular}{|l|l|l|l|l|l|l||}
\hline Source & Year & $\begin{array}{l}\text { Number } \\
\text { of patients }\end{array}$ & $\begin{array}{l}\text { Initial } \\
\text { flaps per } \\
\text { patient }\end{array}$ & $\begin{array}{l}\text { Recurrence: } \\
\text { Number (\%) }\end{array}$ & $\begin{array}{l}\text { Additional } \\
\text { flaps }\end{array}$ & $\begin{array}{l}\text { Mean } \\
\text { follow-up* } \\
\text { (months) }\end{array}$ \\
\hline Michigan (1) & 1989 & 10 & 1.8 & $2(20)$ & 0 & 20 \\
\hline Emory (4) & 1989 & 211 & 1.8 & $12(6)$ & NS & NS \\
\hline $\begin{array}{l}\text { Mayo Clinic } \\
(6)\end{array}$ & 1991 & 100 & 1.9 & $26(26)$ & 10 & 50 \\
\hline $\begin{array}{l}\text { Johns Hopkins } \\
(7)\end{array}$ & 1994 & 135 & 1.6 & $0(0)$ & 0 & ns \\
\hline $\begin{array}{l}\text { Columbia- } \\
\text { Presbyterian } \\
(5)\end{array}$ & 1994 & 74 & 2.0 & $1(1.3)$ & 0 & 37.4 \\
\hline St. Luke's & 1995 & 29 & 1.3 & $6(20.7)$ & 2 & \\
\hline
\end{tabular}

*includes all patients. NS Not stated.

Thirty-nine flaps or 1.3 flaps/patient were required initially (Table 3). The pectoralis major muscle was used by itself in 11 cases, the rectus abdominis muscle solely in four cases, and as a musculocutaneous (VRAM) flap in another seven cases. Four of these rectus flaps were performed even though the internal mammary artery on that side was absent, with success attributed to adequate collateral circulation via the costomarginal branch of the superior epigastric artery (1).

There were four perioperative deaths, due to ongoing renal failure in three, and massive bronchopleural hemorrhage in the other. Three others subsequently died after successful discharge, but none as a consequence of persistant sepsis, with a mean followup time of all survivors of 37.4 months. Six patients had recurrence of a sternal infection 
at a mean of 7.4 months following their median sternotomy for coronary artery bypass graft. Five had residual osteomyelitis identified by bone scan. The cause in one patient remains unknown (case 2). Four resolved with wound drainage or local treatment and culture specific antibiotics. Two required extensive further debridement and additional muscle flap coverage (case reports). No further recurrences in this subset have been observed.

\section{DISCUSSION}

Emphasis for treatment of the infected sternal wound, following adequate debridement, has basically centered about the use of muscle flaps as a direct consequence of the dramatic successes obtained when compared to earlier methods. The pectoralis major muscle remains the most versatile choice when based on its dominant thoracoacromial pedicle, although function preservation techniques using turnover (9) or segmental split flaps (10) can be valuable for some smaller defects if the corresponding internal mammary artery has not been violated. Restricted by this same constraint, the rectus abdominis muscle has been important for filling the lower third of these sternotomy defects $(11,12)$, and rarely should be expected to accomplish more, although a vertical musculocutaneous (VRAM) flap version can be extended to reach most wounds in their entirety as a single flap (13).

Long term outcome studies have shown some concern, even with these workhorse flaps, particularly as regards donor site morbidity $(6,7)$. Abdominal wall hernias and bulges, usually due to use of a rectus abdominis flap, occur in one-third of patients (7). Abdominal weakness is noted in another one-quarter, occurring even if only the pectoralis major muscle has been used (7). Its transfer can also be incriminated as causing shoulder weakness in an additional one-third (7). There has been little discussion of an acknowledged risk of recurrence of sternal infection (Table 3) $(5-7,11,12,14)$. In our experience, recurrences typically present as the type III wounds of Pairolero and Arnold (6) with chronic draining sinuses usually caused by residual osteomyelitis, costochondritis, or a retained foreign body.

Mediastinitis was not present in any of our cases. These could be presumed to be a sequela of inadequate original debridement (15). Although careful elevation and reinsetting of the original flap may be possible following wider debridement (6), one must always be prepared to select another alternative as we indeed have had to do (case reports).

Accrued donor site morbidity and anticipation of future flap requirements serve to validate our admonishment for minimizing the number of flaps transferred initially for any sternal wound. With this in mind, every surgeon should establish a hierarchy of preferences. Our suggested schema (Table 1) is biased toward maximal utilization of the pectoralis major and rectus abdominis muscles with which we are most familiar. Other rarely chosen alternatives include the latissimus dorsi (16) or external oblique (6) muscles, or omentum which requires a laparatomy $(1,3,17)$.

Unfortunately, the rectus abdominis musculocutaneous (VRAM) flap chosen as a sole flap to meet our established criteria in seven patients was complicated by four late infections. This could represent a technical problem on our part as the rectus muscle was never taken below the arcuate line to preserve abdominal wall integrity which was never compromised. Thus the upper third of each sternal defect so closed was devoid of muscle, which we know provides inherent immunological benefits as opposed to dermis or fat 
alone (18). This flap choice must then be suspect as a single flap option for the subacute or chronic sternal wound in spite of perceived advantages in simplifying the extent of surgery for these usually very sick patients. Obviously, further insight is welcome to insure the best initial and long term treatment for the difficult sternal wounds. It is important that the risk of recurrence must be recognized as a not insignificant facet of this problem which must be dealt with appropriately.

ACKNOWLEDGEMENTS: The major care for these patients was provided by William S Hoffman MD and Terrill E Theman MD, Division of Cardiothoracic Surgery, St Luke's Hospital, Bethlehem, Pennsylvania, to whom we are indebted.

\section{REFERENCES}

1. Fernando B, Muszynski C, Mustoe T. Closure of a sternal defect with the rectus abdominis muscle after sacrifice of both internal mammary arteries. Ann Plast Surg 1988;21:468-71.

2. Arnold PG, Pairolero PC. Intrathoracic muscle flaps in the surgical management of life-threatening hemorrhage from the heart and great vessels. Plast Reconstr Surg 1988;81:831-5.

3. Colen LB, Huntsman WT, Morain WD. The integrated approach to suppurative mediastinitis: rewiring the sternum over transposed omentum. Plast Reconstr Surg 1989;84:936-41.

4. Nahai F, Rand RP, Hester TR, Bostwick J, Jurkiewicz MJ. Primary treatment of the infected sternotomy wound with muscle flaps: a review of 211 consecutive cases. Plast Reconstr Surg 1989;84:434-41.

5. Hugo NE, Sultan MR, Ascherman JA, Patsis MC, Smith CR, Rose EA. Single-stage management of 74 consecutive sternal wound complications with pectoralis major myocutaneous advancement flaps. Plast Reconstr Surg 1994;93:1433-41.

6. Pairolero PC, Arnold PG, Harris JB. Long-term results of pectoralis major muscle transposition for infected sternotomy wounds. Ann Surg 1991;213:583-90.

7. Ringelman PR, Vander Kolk CA, Cameron D, Baumgartner WA, Manson PN. Longterm results of flap reconstruction in median sternotomy wound infections. Plast Reconstr Surg 1994;93:1208-14.

8. Solomon MP, Granick MS. New reconstruction method for sternotomy wounds. Perspec Plast Surg 1994;8:61-5.

9. Nahai F, Morales L, Bone DK, Bostwick J. Pectoralis major muscle turnover flaps for closure of the infected sternotomy wound with preservation of form and function. Plast Reconstr Surg 1982;70:471-4.

10. Morain WD, Colen LB, Hutchings JC. The segmental pectoralis major muscle flap: a function-preserving procedure. Plast Reconstr Surg 1985;75:825-30.

11. Iacobucci JJ, Stevenson TR, Hall JD, Deeb GM. Sternal osteomyelitis: treatment with rectus abdominis muscle. Br J Plast Surg 1989;42:452-9.

12. Pairolero PC, Arnold PG. Management of recalcitrant median sternotomy wounds. J Thorac Cardiovasc Surg 1984;88:357-64.

13. Fleischer A. Closure of mediastinal wounds with de-epithelialized rectus abdominis musculocutaneous flaps. Ann Plast Surg 1993;31:146-8. 
14. Majure JA, Albin RE, O'Donnell RS, Arganese TJ. Reconstruction of the infected median sternotomy wound. Ann Thorac Surg 1986;42:9-12.

15. Pairolero PC, Arnold PG. Management of infected median sternotomy wounds. Ann Thorac Surg 1986;42:1-2.

16. Tizian C, Borst HG, Berger A. Treatment of total sternal necrosis using the latissimus dorsi muscle flap. Plast Reconstr Surg 1985;76:703-7.

17. Herrera HR, Ginsburg ME. The pectoralis major myocutaneous flap and omental transposition for closure of infected median sternotomy wounds. Plast Reconstr Surg 1982;70:465-70.

18. Mathes SJ, Alpert BS, Chang N. Use of the muscle flap in chronic osteomyelitis: experimental and clinical correlation. Plast Reconstr Surg 1982;69:815-28. 